\title{
Systemic cytokine signaling via IL- I7 in smokers with obstructive pulmonary disease: a link to bacterial colonization?
}

This article was published in the following Dove Press journal:

International Journal of COPD

27 March 2015

Number of times this article has been viewed

\author{
Kristina Andelid' \\ Sara Tengvall' \\ Anders Andersson' \\ Bettina Levänen ${ }^{2}$ \\ Karin Christenson ${ }^{3}$ \\ Pernilla Jirholt ${ }^{3}$ \\ Christina Åhrén ${ }^{4}$ \\ Ingemar Qvarfordt' \\ Ann Ekberg-Jansson' \\ Anders Lindén ${ }^{2}$ \\ 'Department of Internal Medicine \\ and Clinical Nutrition, Institute \\ of Medicine, Sahlgrenska Academy \\ at the University of Gothenburg, \\ Gothenburg, Sweden; ${ }^{2}$ Unit of Lung \\ and Airway Research, Institute \\ of Environmental Medicine, Karolinska \\ Institutet, Stockholm, Sweden; \\ ${ }^{3}$ Department of Rheumatology \\ and Inflammation Research, \\ Institute of Medicine, ${ }^{4}$ Department \\ of Infectious Diseases, Infection \\ Control Unit, Institute of Biomedicine, \\ Sahlgrenska Academy at the University \\ of Gothenburg, Gothenburg, Sweden
}

Correspondence: Anders Lindén Unit of Lung and Airway Research, Institute of Environmental Medicine, Karolinska Institutet, PO Box 210 , SE-17I77, Stockholm, Sweden Email anders.linden@ki.se
Abstract: We examined whether systemic cytokine signaling via interleukin (IL)-17 and growth-related oncogene- $\alpha$ (GRO- $\alpha$ ) is impaired in smokers with obstructive pulmonary disease including chronic bronchitis (OPD-CB). We also examined how this systemic cytokine signaling relates to bacterial colonization in the airways of the smokers with OPD-CB. Currently smoking OPD-CB patients $(\mathrm{n}=60$, corresponding to Global initiative for chronic Obstructive Lung Disease [GOLD] stage I-IV) underwent recurrent blood and sputum sampling over 60 weeks, during stable conditions and at exacerbations. We characterized cytokine protein concentrations in blood and bacterial growth in sputum. Asymptomatic smokers $(n=10)$ and never-smokers $(n=10)$ were included as control groups. During stable clinical conditions, the protein concentrations of IL-17 and GRO- $\alpha$ were markedly lower among OPD-CB patients compared with never-smoker controls, whereas the asymptomatic smoker controls displayed intermediate concentrations. Notably, among OPD-CB patients, colonization by opportunistic pathogens was associated with markedly lower IL-17 and GRO- $\alpha$, compared with colonization by common respiratory pathogens or oropharyngeal flora. During exacerbations in the OPD-CB patients, GRO- $\alpha$ and neutrophil concentrations were increased, whereas protein concentrations and messenger RNA for IL-17 were not detectable in a reproducible manner. In smokers with OPD-CB, systemic cytokine signaling via IL-17 and GRO- $\alpha$ is impaired and this alteration may be linked to colonization by opportunistic pathogens in the airways. Given the potential pathogenic and therapeutic implications, these findings deserve to be validated in new and larger patient cohorts.

Keywords: COPD, exacerbation, infection, neutrophil, lung, opportunist

\section{Introduction}

Chronic obstructive pulmonary disease is associated with signs of local inflammation in the airways involving neutrophils, macrophages, and T-cells. ${ }^{1}$ There is also emerging evidence that signs of systemic inflammation involving neutrophils are linked to the clinical course in smokers with chronic obstructive pulmonary disease. ${ }^{1,2}$

Interleukin (IL)-17 is an intriguing cytokine that is produced primarily by certain $\mathrm{T}$ helper (Th17) cells but also by cytotoxic T-cells and other immune cells. ${ }^{3-5}$ There is evidence that local cytokine signaling by Th17 cells, via IL-17, is important for antibacterial host defense in the airways. In mammalian airway models, IL-17 induces the release of neutrophil-mobilizing cytokines as well as an accumulation of neutrophils and their antibacterial compounds. ${ }^{6-8}$ Studies on endotoxin exposure and bacterial infections in human airways provide additional support for this idea. ${ }^{9,10}$ From a logical point of view, this indirectly implies that impaired cytokine signaling via IL-17 predisposes for bacterial 
infections and repeated bacterial infections are observed in smokers with chronic obstructive pulmonary disease.

With reference to signs of local inflammation, crosssectional studies have demonstrated increased immunoreactivity (IR) for IL-17 protein in airway cells from smokers and ex-smokers with chronic obstructive pulmonary disease, compared with nonsmoking healthy subjects. ${ }^{3,11,12}$ Given that these findings are compatible with increased as well as decreased extracellular cytokine signaling, it is clear that the assessment of intracellular IR is not as conclusive as that of extracellular protein concentrations. Moreover, none of the previously published studies have related either IR for or extracellular concentrations of IL-17 in chronic obstructive pulmonary disease, to exacerbations or the presence of bacteria in the airways. ${ }^{3,11-15}$ Furthermore, it is known that growthrelated oncogene- $\alpha$ (GRO- $\alpha)$ is a neutrophil-mobilizing effector molecule for IL-17, as demonstrated in airway epithelial, airway smooth muscle, and vascular endothelial cells from humans, comparable to IL-8. ${ }^{16-18}$ There are also data from the peritoneal cavity in mice in vivo suggesting that IL-17-induced release of GRO- $\alpha$ is functionally relevant for neutrophil recruitment. ${ }^{19}$ However, in spite of data suggesting an increase in local GRO- $\alpha$ in smokers with chronic obstructive pulmonary disease, no previous study has addressed the relationship between extracellular IL-17 and GRO- $\alpha$ at the systemic level in these patients. ${ }^{11,16}$

For the current study, we hypothesized that systemic cytokine signaling via IL-17 and GRO- $\alpha$ is impaired in smokers with obstructive pulmonary disease including chronic bronchitis (OPD-CB), in comparison with asymptomatic smokers (AS) and healthy never-smokers (NS). We also hypothesized that this impairment in systemic cytokine signaling relates to the presence and type of bacterial colonization in the airways. To evaluate these hypotheses, we conducted the current prospective, cross-sectional, and longitudinal study, monitoring smokers with OPD-CB over 60 weeks.

\section{Materials and methods Study subjects}

This study was conducted in accordance with national and international ethical standards (see "Supplementary materials"). Briefly, current tobacco smokers ( $n=60,>10$ pack-years) with OPD-CB were recruited from an outpatient clinic and through advertisement. These smokers with OPD-CB were selected in order to increase the likelihood of exacerbations taking place during the study period. At the time of inclusion, these smokers with OPD-CB were all without recent infections. All the smokers with OPD-CB were classified according to the Global initiative for chronic Obstructive Lung Disease (GOLD) criteria for chronic obstructive pulmonary disease (stage I-IV). Ventilatory lung function was assessed without prior bronchodilation, to avoid selection of subjects without reversibility (see also "Discussion" section). The diagnosis of chronic bronchitis was based upon established criteria relating to a history of phlegm at least 3 months in a row, during 2 consecutive years, ascertained by an oral interview and a questionnaire. We excluded patients with lung diseases other than OPD-CB or with regular use of oral glucocorticoids. Patients with other significant clinical diseases or with drug abuse were excluded as well. Four smokers with OPD-CB did not complete the study and their datasets were not included. As control subjects, ten AS (current smokers with $>10$ pack-years) and ten healthy NS were recruited via advertisement, all displaying normal lung function. All subjects underwent urine cotinine tests for evaluation of smoking status. Table 1 presents the clinical characteristics of all included subjects at the time of inclusion under clinically stable conditions.

\section{Study design}

During the inclusion visit, the smokers with OPD-CB were in a clinically stable phase and underwent an interview, physical examination, and assessment of lung function as well as of current smoking (see also "Supplementary materials"). ${ }^{20,21}$ In summary, during the 60-week course of the study, blood, sputum, and urine samples were harvested every 15 th week and during exacerbations. During this study period, exacerbations were diagnosed according to established criteria. ${ }^{22,23}$ Whenever an exacerbation took place, the patient underwent radiological and physical examination and donated samples prior to receiving adequate clinical treatment. The patient's symptoms were then recorded using a validated questionnaire. ${ }^{24}$

Venous blood samples were utilized for the analyses of soluble inflammatory markers and cell differential counts. These analyses included cell differential counts, the quantification of C-reactive (CRP), IL-17, and GRO- $\alpha$ protein plus mRNA for IL-17. The sputum samples from all patients were analyzed for the growth of bacteria after morphological evaluation of representativity. The control subjects attended the inclusion visit only, for sampling matching that of the smokers with OPD-CB.

\section{Statistical methods}

Nonparametric statistics were utilized (see "Supplementary materials"). $P<0.05$ was deemed statistically significant. 
Table I Clinical characteristics of study subjects

\begin{tabular}{|c|c|c|c|}
\hline Study subjects & NS $(n=10)$ & AS $(n=10)$ & OPD-CB $(n=60)$ \\
\hline Age (years) & $68(47-70)$ & $50(26-64)^{*, \circ}$ & $62(45-76)$ \\
\hline Males/females (n) & $3 / 7$ & $2 / 8$ & $26 / 34$ \\
\hline Pack-years & $0(0)$ & $27(12-44)^{*}$ & $40(14-156)$ \\
\hline $\mathrm{FEV}_{1}(\%$ of predicted) & $120(97-137)^{*}$ & $106(83-119)^{*}$ & $60(29-97)$ \\
\hline $\mathrm{FEV}_{1} / \mathrm{FVC}(\mathrm{FEV} \%)$ & $78(73-84)$ & $77(73-84)$ & $55(28-69)$ \\
\hline DLCO (\% of predicted) & $98(75-139)^{*}$ & $87(77-111)^{*}$ & $70(44-110)$ \\
\hline Disease stage $(n)^{a}$ & - & - & \\
\hline I & & & 10 \\
\hline ॥ & & & 31 \\
\hline III & & & 17 \\
\hline IV & & & 2 \\
\hline
\end{tabular}

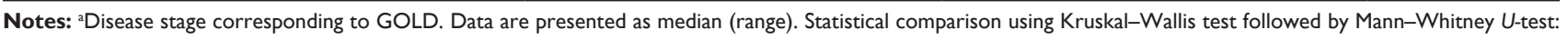
$* P<0.05$ for NS and AS compared to OPD-CB and ${ }^{\circ} P<0.05$ for AS compared to NS.

Abbreviations: NS, never-smokers; AS, asymptomatic smokers; OPD-CB, obstructive pulmonary disease including chronic bronchitis; $\mathrm{FEV}_{1}$, forced expiratory volume in I second; FVC, forced vital capacity; DLCO, gas diffusion capacity for carbon monoxide; GOLD, Global initiative for chronic Obstructive Lung Disease.

\section{Results}

\section{Inclusion during stable clinical conditions} Study population

The characteristics of the study subjects are summarized in Table 1. As a consequence of the inclusion criteria, lung function values were clearly lower in smokers with OPD-CB compared with NS and AS (Table 1). There was also a somewhat higher tobacco load in the smokers with OPD-CB than in the AS controls (Table 1). Moreover, age was lower in AS controls compared with NS and smokers with OPD-CB, respectively (Table 1). The few subjects who were excluded are commented upon in the "Materials and methods" section and in the "Supplementary materials".

\section{IL-I 7 and GRO- $\alpha$ protein in blood}

At the time of inclusion, the smokers with OPD-CB displayed substantially lower blood concentrations for IL-17 and GRO- $\alpha$ protein compared with the NS controls, and these observations were statistically significant (Figure 1). Even though this was not in a statistically significant manner, the concentrations of IL-17 protein tended to be lower in smokers with OPD-CB than in AS controls. However, the concentrations of GRO- $\alpha$ protein were substantially lower in smokers with OPD-CB patients than in AS controls, and this was a statistically significant observation. To evaluate a putative correlation between IL-17 and GRO- $\alpha$ protein in smokers irrespectively of established disease, we pooled the
A

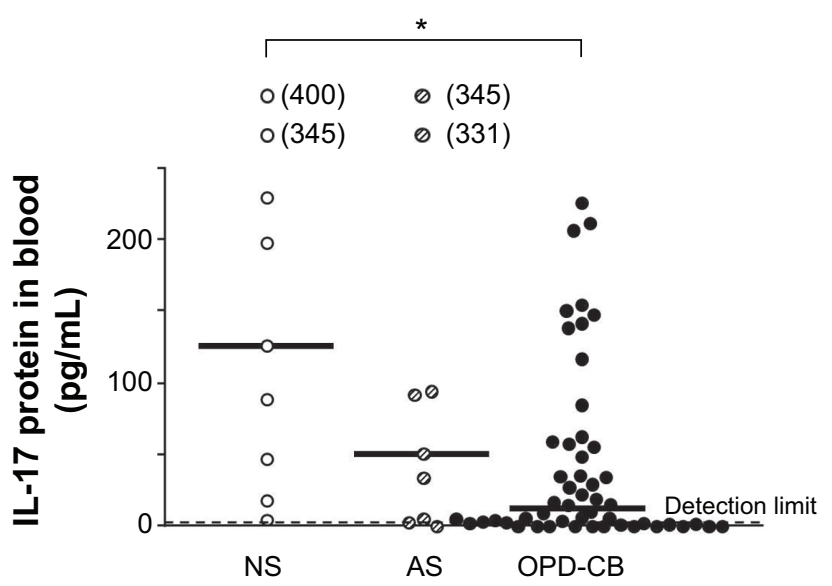

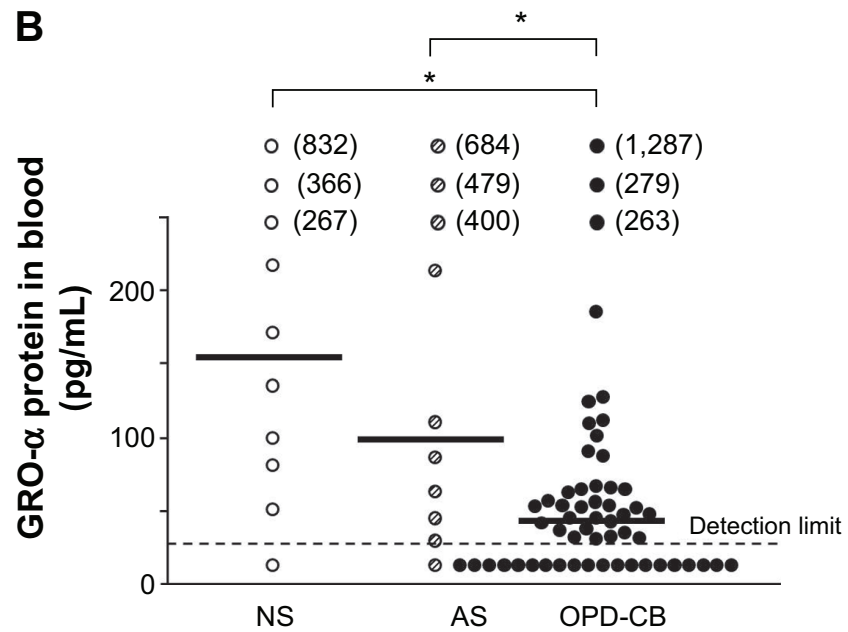

Figure I Concentrations of (A) interleukin (IL)-I7 and (B) growth-related oncogene (GRO)- $\alpha$ protein in blood (see "Materials and methods") harvested from smokers with obstructive pulmonary disease including chronic bronchitis (OPD-CB) during stable conditions at the time of inclusion, compared with never-smokers (NS) and asymptomatic smokers (AS).

Notes: Data are presented as individual (circles) and median (bold lines) values. $* P<0.05$ (Kruskal-Wallis test followed by Mann-Whitney $U$-test). The detection limit of the respective enzyme-linked immunosorbent assay is indicated (dashed line). Numbers in parentheses indicate extreme observations "out of scale". 


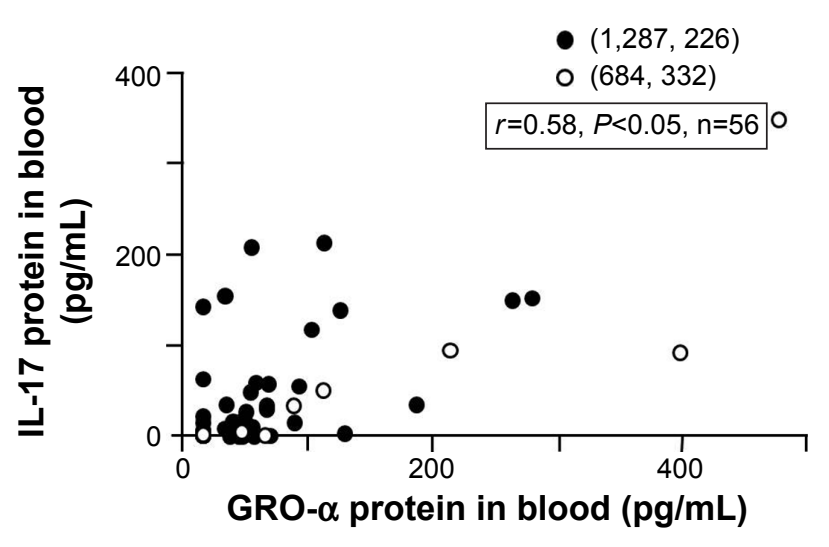

Figure 2 Correlation (Spearman's rank correlation) between the blood concentrations of interleukin (IL)-I7 and growth-related oncogene (GRO)- $\alpha$ protein (see "Materials and methods") harvested from smokers (ie, smokers with obstructive pulmonary disease including chronic bronchitis [filled circles, $n=47$ ] and asymptomatic smokers [open circles, $n=9$ ]) during stable clinical conditions at the time of inclusion. Note: Numbers in parentheses indicate extreme observations "out of scale".

results from smokers with OPD-CB patients with those of the AS controls. We then detected a moderate, positive correlation between IL-17 and GRO- $\alpha$ protein (Figure 2).

We also assessed the stability of blood cytokine concentrations in smokers with OPD-CB that did not develop exacerbations. Here, the median (range) blood cytokine concentrations remained relatively stable over time. For IL-17 $(n=27)$, the concentration at the final visit (week 60) was $100(2-13,129) \%$ of the 15 -week value (3.9 [3.9-512] $\mathrm{pg} / \mathrm{mL})$. Correspondingly, for GRO- $\alpha(\mathrm{n}=16)$, the concentration at the final visit (week 60) was $100(3-1,799) \%$ of the 15 -week value (58.5 [15.5-436] pg/mL).

Furthermore, the impact of severe versus mild disease was addressed in smokers with OPD-CB. We then found that the blood concentrations of IL- 17 but not GRO- $\alpha$ protein tended to be lower in patients with severe disease (corresponding to GOLD stage III+IV) compared to those with mild disease (GOLD stage I+II) (Table 2).

In addition, we addressed the impact of inhaled glucocorticoids on blood cytokine concentrations in smokers with OPD-CB. However, even though we found that treatment with inhaled glucocorticoids tended to be associated with lower blood concentrations of both IL-17 and GRO- $\alpha$, this impact of treatment was statistically significant for GRO- $\alpha$ only (Table 3).

\section{Differential cell counts}

To assess the impact of smoking per se, we pooled the data on neutrophil concentrations from all smokers (OPD-CB plus AS) and compared with the corresponding data from NS controls. We then found that the blood concentrations (median [range]) of neutrophils were increased in a statistically significant manner $(P<0.05)$ in the pooled group of all smokers $\left(4.3[2.0-9.6] \times 10^{9} / \mathrm{L}, \mathrm{n}=70\right)$ compared with NS controls $\left(2.8[1.8-4.7] \times 10^{9} / \mathrm{L}, \mathrm{n}=10\right)$. Among smokers with OPD-CB, the concentrations of all leukocytes, as well as those of neutrophils and lymphocytes, were lower in subjects with severe disease than in those with mild disease, and those observations proved statistically significant (Table 2). Notably, in subjects with severe disease, the concentrations of neutrophils and GRO- $\alpha$ protein displayed a moderate correlation ( $r=0.55, P=0.03, \mathrm{n}=19)$ (Figure 3). No basophils were identified in the blood samples of either study group.

\section{CRP}

To verify that our population of smokers with OPD-CB were representative, we compared the concentrations of CRP in this group with those in AS and NS controls. We found that the CRP concentrations were higher among smokers with OPD-CB compared with the AS and NS controls (data not shown). However, there were no substantial differences in CRP concentrations for subjects with mild and severe disease (Table 2). Notably, in the entire group of smokers with OPD-CB, the concentrations of CRP and GRO- $\alpha$ displayed a weak correlation ( $r=0.34, P=0.01, \mathrm{n}=55$ ) and, within the group of smokers with severe OPD-CB, a relatively strong correlation ( $r=0.66, P=0.006, \mathrm{n}=16$ ). In contrast, there was no corresponding correlation ( $r=0.14, P=0.26, \mathrm{n}=64)$ in the pooled group of all smokers (OPD-CB plus AS). Moreover, as expected, the CRP concentrations displayed weak correlations with blood neutrophil concentrations and pack-years among all smokers (OPD-CB plus AS) (data not shown). However, the CRP concentrations did not correlate either with IL-17, leukocyte, or lymphocyte concentrations (data not shown).

Table 2 Inflammatory cells and cytokines in the blood for mild and severe OPD-CB

\begin{tabular}{lllllll}
\hline Disease severity & IL- I $7(\mathbf{p g} / \mathbf{m L})$ & GRO- $\alpha(\mathbf{p g} / \mathbf{m L})$ & Leuko $\left(\times 10^{9} / \mathbf{L}\right)$ & Neu $\left(\times 10^{9} / \mathbf{L}\right)$ & Lym $\left(\times 10^{9} / \mathbf{L}\right)$ & CRP $(\mathbf{m g} / \mathbf{L})$ \\
\hline Mild $^{\mathrm{a}}(\mathrm{n}=40)$ & $17.3(0.8-15 I)$ & $44.0(15.5-279)$ & $8.2(4.8-14.6)$ & $4.6(2.3-9.6)$ & $2.3(1.2-4.5)$ & $2.0(0.3-19.0)$ \\
Severe $^{\mathrm{b}}(\mathrm{n}=20)$ & $10.4(0.8-226)$ & $47.0(15.5-1,287)$ & $6.5(3.9-11.5)^{*}$ & $3.9(2.0-9.6)^{*}$ & $1.7(0.9-3.4)^{*}$ & $1.6(0.3-19.0)$ \\
\hline
\end{tabular}

Notes: a OPD-CB corresponding to GOLD stage I and II; ' $\mathrm{OPD}-\mathrm{CB}$ corresponding to GOLD stage III and IV. Data are presented as median (range). Statistical comparison using Kruskal-Wallis test followed by Mann-Whitney U-test: $* P<0.05$ for comparison of mild and severe OPD-CB.

Abbreviations: IL-17, interleukin I7; GRO- $\alpha$, growth-related oncogene- $\alpha$; Leuko, leukocytes; Neu, neutrophils; Lym, lymphocytes; CRP, C-reactive protein; OPD-CB, obstructive pulmonary disease including chronic bronchitis; GOLD, Global initiative for chronic Obstructive Lung Disease. 
Table 3 Impact of inhaled glucocorticoids on inflammatory cells and cytokines in the blood of smokers with OPD-CB

\begin{tabular}{|c|c|c|c|c|c|c|}
\hline Inhaled GC & IL-I 7 (pg/mL) & GRO- $\alpha(\mathrm{pg} / \mathrm{mL})$ & Leuko $\left(\times 10^{9} / \mathrm{L}\right)$ & Neu $\left(\times 10^{9} / L\right)$ & $\operatorname{Lym}\left(\times 10^{9} / L\right)$ & CRP (mg/L) \\
\hline $\mathrm{GC}(n=31-38)$ & $6.4(0.8-226)$ & $33(|5.5-|, 287)$ & $7.1(4.8-11.5)$ & $4.4(2.3-9.6)$ & $1.9(0.9-4.4)$ & I.7 (0.3-19.0) \\
\hline No GC $(n=16-22)$ & $35(0.8-|5|)$ & $55(\mid 5.5-279)^{*}$ & $7.8(3.9-14.6)$ & $4.3(2.0-9.6)$ & $2.6(1.0-4.5)^{*}$ & $2.1(0.5-9.5)$ \\
\hline
\end{tabular}

Notes: Data are presented as median (range). Statistical comparison using Kruskal-Wallis test followed by Mann-Whitney U-test: *P $<0.05$ compared with GC+.

Abbreviations: GC, glucocorticoids; IL-I7, interleukin I7; GRO- $\alpha$, growth-related oncogene- $\alpha$; Leuko, leukocytes; Neu, neutrophils; Lym, lymphocytes; CRP, C-reactive protein.

\section{IL-I7 and GRO- $\alpha$ protein in blood versus lung function and tobacco load}

Within the pooled group of all study subjects, there was no correlation between the concentrations of IL-17 protein, GRO- $\alpha$ protein, and inflammatory cells, on the one hand, and forced expiratory volume in 1 second $\left(\mathrm{FEV}_{1}\right)$, gas diffusion capacity for carbon monoxide, or pack-years, on the other hand (data not shown). However, there was a weak, positive correlation between GRO- $\alpha$ concentrations and $\mathrm{FEV}_{1}$ within the pooled group of all study subjects (OPD-CB, AS, and NS) (Figure S1).

\section{Bacteria in sputum samples}

At the time of inclusion, sputum samples were obtained in 52 out of $60(87 \%)$ smokers with OPD-CB. Among these, samples from 12 smokers with OPD-CB were deemed not representative for the peripheral airways due to the cellular morphology and were thus excluded, leaving 40 representative samples. Out of these representative samples, three samples displayed growth of opportunistic pathogens (ie, pathogens not normally found the airways), including Escherichia coli $(\mathrm{n}=1)$, Pseudomonas aeruginosa $(\mathrm{n}=1)$, and Stenotrophomonas maltophilia $(\mathrm{n}=1)$. Here, one sample displayed growth of two bacterial species ( $P$. aeruginosa plus Enterobacter agglomerans). Moreover, 17 samples displayed growth of common respiratory pathogens, including Haemophilus influenzae $(\mathrm{n}=5)$, Streptococcus pneumoniae $(\mathrm{n}=2)$, Moraxella catarrhalis $(\mathrm{n}=1)$, and Haemophilus parainfluenzae $(\mathrm{n}=9)$. Finally, 20 samples displayed growth of oropharyngeal flora.

\section{IL-I 7 and GRO- $\alpha$ protein in blood versus bacteria in sputum samples}

We grouped the blood cytokine concentrations for smokers with OPD-CB who had representative samples displaying growth of the three principally different types of bacteria (see "Bacteria in sputum samples" above).

The median (range) IL-17 protein concentrations tended to be lower in the few smokers with OPD-CB displaying growth of opportunistic pathogens $(2.0[0.8-4.1] \mathrm{pg} / \mathrm{mL}, \mathrm{n}=3)$ compared with the corresponding smokers displaying growth of either common respiratory pathogens (32.6 [0.8-211.5] $\mathrm{pg} / \mathrm{mL}, \mathrm{n}=12$ ) or oropharyngeal flora $(56[0.8-225.7] \mathrm{pg} / \mathrm{mL}$, $\mathrm{n}=15)$. We therefore compared the concentrations of IL-17 protein for the smokers with OPD-CB who had growth of opportunistic pathogens (see Bacteria in sputum samples section) with those who had growth of either common respiratory pathogens or oropharyngeal flora $(35[0.8-225.7] \mathrm{pg} / \mathrm{mL}$, $\mathrm{n}=27$ ) and found the difference to be statistically significant (Kruskal-Wallis test: $P=0.02$ ).

Similar to the case for IL-17, the median (range) GRO- $\alpha$ protein concentrations tended to be lower in the few smokers with OPD-CB displaying growth of opportunistic pathogens $(15.5$ [15.5-15.5] pg/mL, $\mathrm{n}=3)$ compared with the corresponding smokers displaying growth of either common respiratory pathogens $(67$ [15.5-279] $\mathrm{pg} / \mathrm{mL}, \mathrm{n}=15)$ or oropharyngeal flora $(55[15.5-1,287] \mathrm{pg} / \mathrm{mL}, \mathrm{n}=18)$. We therefore compared the concentrations of GRO- $\alpha$ protein for the smokers with OPD-CB who had growth of opportunistic pathogens (above) with those who had growth of either common respiratory pathogens or oropharyngeal flora $(56.0[15.5-279] \mathrm{pg} / \mathrm{mL}, \mathrm{n}=21)$ and found the difference to be statistically significant (Kruskal-Wallis test: $P=0.04$ ), in analogy to what was the case for IL-17.

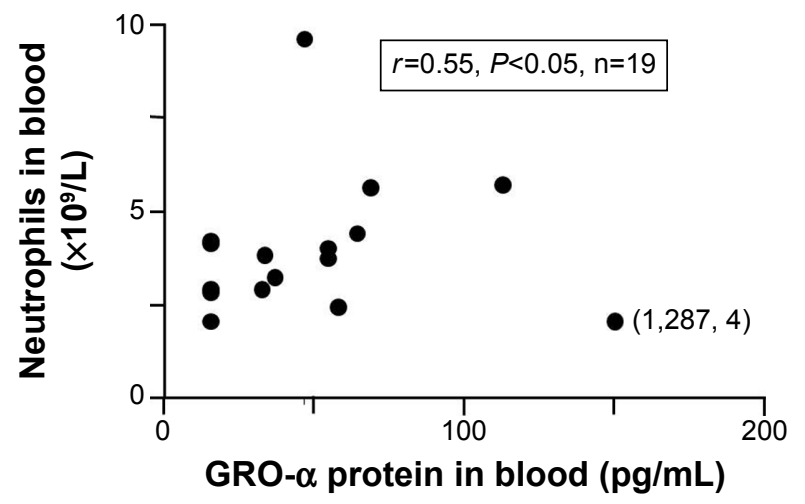

Figure 3 Correlation between the concentrations of neutrophils and growth-related oncogene (GRO)- $\alpha$ protein (Spearman's rank correlation) in blood (see "Materials and methods") from smokers with obstructive pulmonary disease including chronic bronchitis having severe disease (corresponding to stage III+IV) according to the Global initiative for chronic Obstructive Lung Disease (GOLD) during stable clinical conditions at the time of inclusion.

Note: Numbers in parentheses indicate extreme observations "out of scale". 


\section{mRNA for IL-I7}

The relative level of IL-17 mRNA in blood was quantified to assess transcription in blood cells but it was below the detection limit in all samples (data not shown). However, mRNA for the housekeeping gene $\beta$-actin was clearly detectable in the very same samples (data not shown).

\section{Exacerbations in smokers with OPD-CB} Frequency of exacerbations

Thirty-eight (63\%) of the smokers with OPD-CB suffered from at least one exacerbation during the 60 weeks of study. Out of these smokers, nine had a second and seven had a third exacerbation. Due to limitations of statistical power, we focused our analysis on the data from the first exacerbation.

\section{IL-I 7 and GRO- $\alpha$ protein in blood}

Among the smokers with OPD-CB who actually developed exacerbations, the blood concentrations of IL-17 protein were very low; in fact, they were undetectable in the majority of samples. As a consequence of this and the detection method available, we were unable to demonstrate an alteration in these concentrations during exacerbations (Figure 4A). In contrast, the blood concentrations of GRO- $\alpha$ protein were detectable in the majority of samples (Figure 4B). These concentrations were increased during exacerbations in a reproducible manner, in comparison with corresponding concentrations in the samples harvested at the most recent visit prior to the exacerbation. During the first visit after exacerbation, however, the blood concentrations of GRO- $\alpha$ protein tended to become normalized.

A

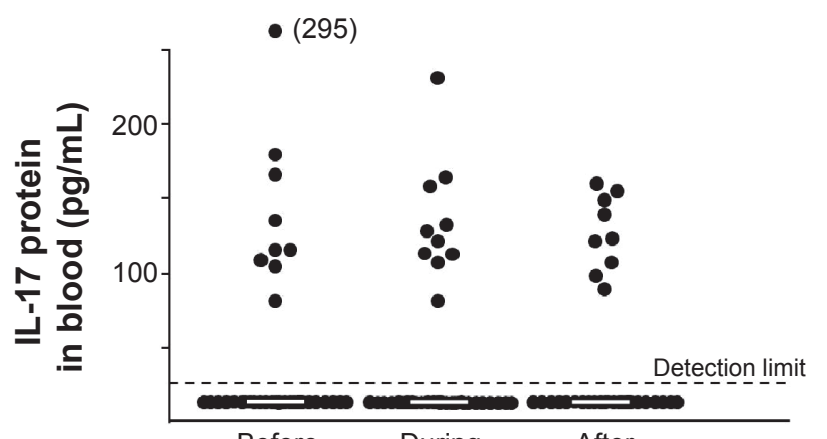

We also compared smokers with OPD-CB who had more than one exacerbation with the smokers from the same group who had no or one exacerbation. We then found that the median (range) blood concentration of IL-17 protein tended to be lower among the smokers with more frequent exacerbations $(6.4$ [0.8-207] pg/mL, $\mathrm{n}=13)$ compared with those with no or one exacerbation $(15.6[0.8-226] \mathrm{pg} / \mathrm{mL}$, $\mathrm{n}=34)$, but this difference was far from statistically significant $(P=0.8)$. A similar pattern was observed for GRO- $\alpha$ protein $(37.3$ [16-67] versus $49[16-1,287] \mathrm{pg} / \mathrm{mL}, \mathrm{n}=15-41$, $P=0.2)$ and for neutrophils $\left(4.1[2.4-9.6] \times 10^{9} / \mathrm{L}\right.$ versus 4.4 [2-9.6] $\left.\times 10^{9} / \mathrm{L}, \mathrm{n}=16-43, P=0.8\right)$.

\section{Differential cell counts}

The concentrations of total leukocytes and of neutrophils only increased during exacerbations (Table S1). We did not find any correlation between blood concentrations of IL-17 or GRO- $\alpha$ protein, on the one hand, and differential cell counts, on the other hand. No basophils were identified in the blood samples of either study group.

\section{CRP}

The concentrations of CRP increased in a reproducible manner during exacerbations (Table S1).

\section{Bacteria in sputum samples}

Of the 29 representative sputum culture samples that were collected during exacerbations in smokers with OPD-CB, none displayed growth of opportunistic pathogens. However, 14 (48\%) displayed growth of respiratory pathogens, including H. influenzae (n=6), S. pneumoniae $(\mathrm{n}=4)$, M. catarrhalis

B

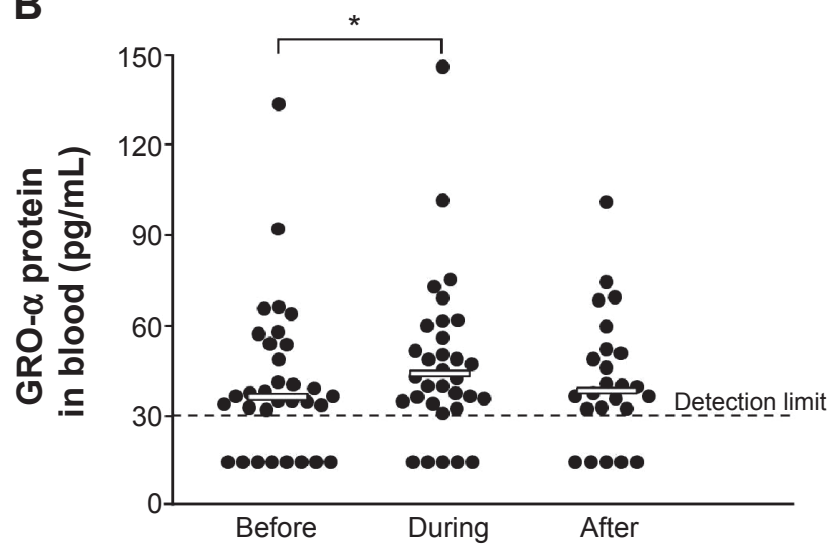

Figure 4 Comparisons of the concentrations of (A) interleukin (IL)- 17 ( $n=34-38)$ and (B) growth-related oncogene (GRO)- $\alpha$ protein ( $n=24-32)$ in blood (see "Materials and methods") from smokers with obstructive pulmonary disease including chronic bronchitis before, during, and after the first exacerbation.

Notes: Data are presented as individual (filled circles) and median (bold white lines) values. The detection limit of the respective enzyme-linked immunosorbent assay is indicated (dashed line). ${ }^{*} P<0.05$; (Kruskal-Wallis test followed by Mann-Whitney U-test). Numbers in parentheses indicate extreme observations "out of scale". 
$(\mathrm{n}=2)$, and $H$. parainfluenzae $(\mathrm{n}=2)$. The remaining 15 samples displayed growth of oropharyngeal flora.

Notably, there was no evident consistency of bacterial growth at inclusion and during exacerbations within individual smokers with OPD-CB (Figure S2). In one case only, the same bacterial species ( $S$. pneumoniae) was detected on both occasions. Among the smokers with OPD-CB that harbored respiratory pathogens at the time of inclusion, only $29 \%$ (four out of 14 ) of smokers also harbored respiratory pathogens during exacerbations (Figure S2).

\section{mRNA for IL- I7}

The relative level of IL-17 mRNA in blood was quantified to assess transcription in blood cells but it was below the detection limit in all samples (data not shown). However, mRNA for the housekeeping gene $\beta$-actin was clearly detectable in the very same samples (data not shown).

\section{Discussion}

We characterized systemic cytokine signaling via extracellular IL-17 and GRO- $\alpha$ protein in smokers with OPD-CB, during stable clinical conditions and exacerbations. During stable clinical conditions, the blood concentrations of IL-17 and GRO- $\alpha$ protein were markedly lower among smokers with OPD-CB than among NS controls and tended to be less decreased in AS controls. However, due to undetectable IL-17 protein concentrations among many of the smokers with OPD-CB that actually developed exacerbations, we were unable to demonstrate an exacerbation-related alteration in IL-17 blood concentrations. In contrast, we detected increased blood concentrations of GRO- $\alpha$ protein and neutrophils during exacerbations. Notably, in smokers with OPD-CB who did not develop exacerbations, blood concentrations of IL-17 and GRO- $\alpha$ remained relatively low and stable over time. Thus, we obtained evidence for impaired systemic cytokine signaling via extracellular IL-17 and GRO- $\alpha$ during stable clinical conditions in smokers with OPD-CB and an increased systemic cytokine signaling via GRO- $\alpha$ during exacerbations.

Cytokine signaling via IL-17 and GRO- $\alpha$ is believed to be important for antibacterial host defense in several ways. Thus, collectively, the effects of IL-17 and GRO- $\alpha$ include stimulation of the granulopoiesis, the local accumulation of neutrophils and their antibacterial compounds, the recruitment of macrophage precursor cells, and the survival of mature airway macrophages. ${ }^{78}$ Given these effects, it is logical that smokers with OPD-CB, who are susceptible to bacterial colonization and infection, may suffer from an impaired cytokine signaling involving IL-17 and GRO- $\alpha .{ }^{7,8}$ To date, ours is the first longitudinal and cross-sectional study attempting to address these matters at the systemic level in smokers with OPD-CB of both sexes, during stable clinical conditions and exacerbations. ${ }^{13,25}$

Our demonstration of impaired cytokine signaling via IL-17 during stable clinical conditions in current smokers with OPD-CB is in line with findings by Zhang et al even though these authors did not separate AS, current smokers, and NS for the control group, and no female subjects were included. ${ }^{25}$ In contrast, Vargas-Rojas et al forwarded seemingly conflicting evidence, indicating that the blood concentrations of Th17 cells, potential sources of IL-17, are increased in patients with chronic obstructive pulmonary disease compared with relevant controls. ${ }^{13}$ However, extracellular IL-17 protein concentrations were not assessed in their study and it is unclear to what extent the investigated patients were in a stable clinical condition. When smokers with and without chronic obstructive pulmonary disease plus healthy controls were pooled in the study by Vargas-Rojas et al then there was a negative correlation between Th17 cell counts in blood and $\mathrm{FEV}_{1} \cdot{ }^{13}$ In contrast, when we assessed blood concentrations of extracellular IL-17 protein, a functionally more relevant outcome than Th17 cell counts, we did not find this type of correlation with $\mathrm{FEV}_{1}$ (data not shown). Of note, a more recent study by Zhang et al indicated increased systemic cytokine signaling via extracellular IL-17 in chronic obstructive pulmonary disease, an increase that correlated with disease severity. ${ }^{26}$ Possibly, the basis for this discrepancy relates to the measurement of IL-17 in serum samples and the inconsistent handling of chronic bronchitis in the study by Zhang et al. ${ }^{26}$

In support of our observation of decreased blood concentrations of extracellular IL-17 protein in smokers with OPD-CB, we detected a trend toward decreased blood concentrations of extracellular IL-17 protein in the smokers with severe disease compared with those with mild disease. In line with this, Paats et al recently demonstrated that low proportions of IL-17-expressing T-cells in blood are associated with a reduced gas diffusion capacity in patients with severe chronic obstructive pulmonary disease.${ }^{27}$ Collectively, these results are compatible with even more impairment of systemic cytokine signaling via extracellular IL-17 in smokers with severe chronic obstructive pulmonary disease.

In hindsight, it is not surprising that we failed to reproducibly detect IL-17 protein concentrations during exacerbations among the current smokers with OPD-CB. The entire group of these smokers did display low or undetectable concentrations of IL-17 in plasma samples already during stable clinical conditions at the time of inclusion. By definition, the smokers 
with OPD-CB developing exacerbations are likely to represent a selected group with more severe disease and propensity for airway infections. In line with their low blood concentrations of IL-17, these smokers displayed no detectable transcription of mRNA for IL-17 in blood cells at any time point. Indeed, this also raises the question whether posttranslational mechanisms or "spillover" of cytokines from the lungs contributes to systemic cytokine signaling in chronic obstructive pulmonary disease.

The previous demonstration of increased concentrations of GRO- $\alpha$ protein locally in the airways during stable clinical conditions in chronic obstructive pulmonary disease contrasts to the more recent observation of blood concentrations of GRO- $\alpha$ tending to be decreased in patients with chronic obstructive pulmonary disease. ${ }^{11,28}$ Notably, Liu et al showed that the blood concentrations of GRO- $\alpha$ correlate with the use of glucocorticoids, but not with ventilatory lung function, in a negative manner. ${ }^{28}$ We now expand and provide support for this finding by proving decreased serum concentrations of extracellular GRO- $\alpha$ protein during stable clinical conditions in smokers with OPD-CB, in comparison with two relevant control groups (AS and NS). We also proved a positive correlation between GRO- $\alpha$ and $\mathrm{FEV}_{1}$ in the pooled group of all study subjects, compatible with systemic cytokine signaling via GRO- $\alpha$ being pathogenically relevant. Furthermore, we found a positive correlation between IL-17 and GRO- $\alpha$ protein in the pooled group of all smokers (OPD-CB and AS), compatible with the idea that IL-17 signals via GRO- $\alpha$. Finally, the positive correlation between GRO- $\alpha$ and neutrophil concentrations in the smokers with severe OPD-CB is compatible with a neutrophil-mobilizing role of GRO- $\alpha$.

It may appear contradictive that, whereas IL-17 concentrations remained undetectable during exacerbations, we detected increased concentrations of GRO- $\alpha$ and neutrophils during exacerbations. This is because the idea that GRO- $\alpha$ constitutes a downstream effector molecule of IL-17 implies that its increase should be matched by IL-17. However, our lack of a sufficiently sensitive method for detecting IL-17 in the current setting does not rule out an exacerbation-associated increase - an increase may still take place within the undetectable range. Moreover, even if GRO- $\alpha$ serves as a downstream effector molecule for cytokine signaling via IL-17, it is feasible that the release of GRO- $\alpha$ also can be induced by additional stimuli, including bacterial compounds. ${ }^{29-31}$ Our detection of a relatively strong correlation between CRP, an archetype marker of systemic inflammation, and GRO- $\alpha$ in the group of smokers with severe OPD-CB is also compatible with additional mechanisms driving GRO- $\alpha$ at the systemic level.
Reservations for statistical power must be forwarded, given the small number of the studied smokers with OPD-CB that were proven to be colonized by opportunistic pathogens in the airways. Nevertheless, the association of this opportunistic colonization with impaired cytokine signaling via IL-17 and GRO- $\alpha$, in smokers with OPD-CB, may have important pathogenic implications. The main argument for this is that bacterial colonization in the airways is a risk factor for repeated infections and the involvement of IL-17 and Th17 cells in host defense of mammalian lungs in vivo, at the local and the systemic level. ${ }^{8-10}$ Our current identification of an association between systemic cytokine signaling and opportunistic colonization therefore warrants new studies on larger patient cohorts for validation.

Most likely, the smokers with OPD-CB in our current study represent the chronic bronchitis phenotype of chronic obstructive pulmonary disease. This is because all included subjects denied a history of asthma and allergy, or displayed a negative sensitization test, and all had a long history of tobacco smoking. As expected, we found higher concentrations of neutrophils in all smokers (OPD-CB plus AS) compared to the NS controls. We also found that CRP concentrations correlated with tobacco load among the pooled group of smokers (data not shown) and CRP concentrations were higher in smokers with OPD-CB compared to the AS and NS control groups. In addition, the concentrations of CRP and neutrophils were increased during exacerbations. All these observations illustrate typical features of chronic obstructive pulmonary disease. ${ }^{14,25,32}$ In addition, we observed that the concentrations of total leukocytes, neutrophils, and lymphocytes were lower in current smokers with severe OPD-CB than in those with mild OPD-CB during stable clinical conditions. Interestingly, the latter implies that there is a generic, systemic impairment of host defense in smokers with severe OPD-CB.

It is true that we cannot rule out that we included some smokers with reversible airway obstruction, given that we did not screen for reversibility of airway obstruction. However, if a substantial number of smokers with reversible airway obstruction due to asthma had been included, this should have resulted in an increased average concentration of IL-17 in blood samples, because IL-17 is known to be increased both locally and systemically in asthma. ${ }^{28,29}$ In contrast to what is expected in asthma, we found decreased blood concentrations of IL-17 in our smokers with OPD-CB.

It should be emphasized that our current study results may have therapeutic implications. This is because we obtained evidence that treatment with inhaled glucocorticoids is 
associated with decreased systemic cytokine signaling via GRO- $\alpha$, and there was a similar trend for IL-17 as well. This is of clinical interest, given our evidence for an association of decreased cytokine signaling and opportunistic colonization. Another aspect is that the ongoing therapeutic development of systemic administration of anti-IL-17 antibodies for patients with asthma, in whom systemic cytokine signaling via IL-17 is increased, is disputable for patients with chronic obstructive pulmonary disease, in whom the same cytokine signaling evidently is decreased..$^{28,29}$

\section{Conclusion}

Our study results confirm the hypothesis that systemic cytokine signaling via IL-17 and GRO- $\alpha$ is impaired in smokers with OPD-CB during stable clinical conditions and provide evidence that this impairment is associated with bacterial colonization by opportunistic pathogens locally in the airways. However, for statistical reasons, the latter finding is in need of validation in new and larger cohorts of chronic obstructive pulmonary disease, to clarify the potentially important pathogenic and therapeutic implications of our current findings.

\section{Acknowledgments}

The authors gratefully acknowledge the expert advice from statistician Max Wikström, PhD, Unit for Cardiovascular Epidemiology, Institute of Environmental Medicine, Karolinska Institutet. The authors would like to thank Barbro Balder, MSc, the Section of Respiratory Medicine, Sahlgrenska University Hospital, for excellent clinical monitoring of the study subjects. Project funding was obtained from the HeartLung Foundation (\#20130294) and from King Gustav V's and Queen Victoria's Freemason Research Foundation. Authors KA and AE-J were partially funded by Angered Local Hospital in the Västra Götaland Region. Federal funding was obtained from Karolinska Institutet and, in accordance with the ALF and LUA agreement, from Stockholms Läns Landsting and the Västra Götaland Region, respectively.

\section{Disclosure}

No funding was obtained from the tobacco industry, and the authors report no conflicts of interest in this work.

\section{References}

1. Barbu C, Iordache M, Man MG. Inflammation in COPD: pathogenesis, local and systemic effects. Rom J Morphol Embryol. 2011;52:21-27.

2. Nussbaumer-Ochsner Y, Rabe KF. Systemic manifestations of COPD. Chest. 2011;139:165-173.

3. Eustace A, Smyth LJ, Mitchell L, Williamson K, Plumb J, Singh D. Identification of cells expressing IL-17A and IL-17F in the lungs of patients with COPD. Chest. 2011;139:1089-1100.
4. Hueber AJ, Asquith DL, Miller AM, et al. Mast cells express IL-17A in rheumatoid arthritis synovium. J Immunol. 2010;184:3336-3340.

5. Pappu R, Ramirez-Carrozzi V, Ota N, Ouyang W, Hu Y. The IL-17 family cytokines in immunity and disease. $J$ Clin Immunol. 2010;30:185-195.

6. Zúñiga LA, Jain R, Haines C, Cua DJ. Th17 cell development: from the cradle to the grave. Immunol Rev. 2013;252:78-88.

7. Laan M, Cui ZH, Hoshino H, et al. Neutrophil recruitment by human IL-17 via C-X-C chemokine release in the airways. J Immunol. 1999; 162:2347-2352

8. Kolls JK, Lindén A. Interleukin-17 family members and inflammation. Immunity. 2004;21:467-476.

9. Glader P, Smith ME, Malmhäll C, et al. Interleukin-17-producing T-helper cells and related cytokines in human airways exposed to endotoxin. Eur Respir J. 2010;36:1155-1164.

10. Paats MS, Bergen IM, Hanselaar WE, et al. T helper 17 cells are involved in the local and systemic inflammatory response in communityacquired pneumonia. Thorax. 2013;68:468-474.

11. Di Stefano A, Caramori G, Gnemmi I, et al. T helper type 17-related cytokine expression is increased in the bronchial mucosa of stable chronic obstructive pulmonary disease patients. Clin Exp Immunol. 2009; 157:316-324.

12. Doe C, Bafadhel M, Siddiqui S, et al. Expression of the T helper 17-associated cytokines IL-17A and IL-17F in asthma and COPD. Chest. 2010;138:1140-1147.

13. Vargas-Rojas MI, Ramírez-Venegas A, Limón-Camacho L, Ochoa L, Hernández-Zenteno R, Sansores RH. Increase of Th17 cells in peripheral blood of patients with chronic obstructive pulmonary disease. Respir Med. 2011;105:1648-1654.

14. Hogg JC, Chu F, Utokaparch S, et al. The nature of small-airway obstruction in chronic obstructive pulmonary disease. $N$ Engl $J$ Med. 2004;350:2645-2653.

15. Wang H, Ying H, Wang S, et al. Imbalance of peripheral blood Th17 and Treg responses in patients with chronic obstructive pulmonary disease. Clin Respir J. Epub 2014 Apr 11.

16. Prause O, Laan M, Lötvall J, Lindén A. Pharmacological modulation of interleukin-17-induced GCP-2-, GRO-alpha- and interleukin-8 release in human bronchial epithelial cells. Eur J Pharmacol. 2003;462: 193-198.

17. Jones CE, Chan K. Interleukin-17 stimulates the expression of interleukin-8, growth-related oncogene-alpha, and granulocyte-colonystimulating factor by human airway epithelial cells. Am J Respir Cell Mol Biol. 2002;26:748-753.

18. Bosteen MH, Tritsaris K, Hansen AJ, Dissing S. IL-17A potentiates $\mathrm{TNF} \alpha$-induced secretion from human endothelial cells and alters barrier functions controlling neutrophils rights of passage. Pflugers Arch. 2014;466:961-972.

19. Witowski J, Pawlaczyk K, Breborowicz A, et al. IL-17 stimulates intraperitoneal neutrophil infiltration through the release of GRO alpha chemokine from mesothelial cells. J Immunol. 2000;165: 5814-5821.

20. Quanjer PH, Tammeling GJ, Cotes JE, Pedersen OF, Peslin R, Yernault JC. Lung volumes and forced ventilatory flows. Report Working Party Standardization of Lung Function Tests, European Community for Steel and Coal. Official Statement of the European Respiratory Society. Eur Respir J Suppl. 1993;16:5-40.

21. Salorinne Y. Single-breath pulmonary diffusing capacity. Reference values and application in connective tissue diseases and in various lung diseases. Scand J Respir Dis Suppl. 1976;96:1-84.

22. Wedzicha JA, Donaldson GC. Exacerbations of chronic obstructive pulmonary disease. Respir Care. 2003;48:1204-1213; discussion 1213-1215.

23. Anthonisen NR, Manfreda J, Warren CP, Hershfield ES, Harding GK, Nelson NA. Antibiotic therapy in exacerbations of chronic obstructive pulmonary disease. Ann Intern Med. 1987;106:196-204.

24. Burney PG, Luczynska C, Chinn S, Jarvis D. The European Community Respiratory Health Survey. Eur Respir J. 1994;7:954-960. 
25. Zhang $\mathrm{X}$, Zheng $\mathrm{H}$, Zhang $\mathrm{H}$, et al. Increased interleukin (IL)-8 and decreased IL-17 production in chronic obstructive pulmonary disease (COPD) provoked by cigarette smoke. Cytokine. 2011;56:717-725.

26. Zhang L, Cheng Z, Liu W, Wu K. Expression of interleukin (IL)-10, IL-17A and IL-22 in serum and sputum of stable chronic obstructive pulmonary disease patients. COPD. 2013;10:459-465.

27. Paats MS, Bergen IM, Hoogsteden HC, van der Eerden MM, Hendriks RW. Systemic $\mathrm{CD}^{+}$and $\mathrm{CD} 8^{+} \mathrm{T}$-cell cytokine profiles correlate with GOLD stage in stable COPD. Eur Respir J. 2012;40:330-337.

28. Liu SF, Chin CH, Wang CC, Lin MC. Correlation between serum biomarkers and BODE index in patients with stable COPD. Respirology. 2009;14:999-1004.

29. Witherden IR, Vanden Bon EJ, Goldstraw P, Ratcliffe C, Pastorino U, Tetley TD. Primary human alveolar type II epithelial cell chemokine release: effects of cigarette smoke and neutrophil elastase. Am J Respir Cell Mol Biol. 2004;30:500-509.
30. Beck GCh, Yard BA, Schulte J, et al. Inhibition of LPS-induced chemokine production in human lung endothelial cells by lipid conjugates anchored to the membrane. Br J Pharmacol. 2002;135:1665-1674.

31. Rittig MG, Kaufmann A, Robins A, et al. Smooth and rough lipopolysaccharide phenotypes of Brucella induce different intracellular trafficking and cytokine/chemokine release in human monocytes. J Leukoc Biol. 2003;74:1045-1055.

32. Sutherland ER, Martin RJ. Airway inflammation in chronic obstructive pulmonary disease: comparisons with asthma. J Allergy Clin Immunol. 2003;112:819-827; quiz 828. 


\section{Supplementary materials \\ Materials and methods \\ Ethics}

This study was conducted in accordance with the Helsinki Declaration, and informed consent was obtained with both oral and written information from each participating subject. The approval numbers from the Regional Ethics Committee for Medical Research at the University of Gothenburg were as follows: S233-03, T286-04, and T521-06.

\section{Study subjects}

Current smokers with obstructive pulmonary disease including chronic bronchitis (OPD-CB) were recruited from the outpatient clinic at the Section of Respiratory Medicine at Sahlgrenska University Hospital, Gothenburg, Sweden, and by advertising in the local press (Metro ${ }^{\circledR}$, Gothenburg, Sweden). Finally, we included 60 smokers with OPD-CB during stable clinical conditions, after each one of these had declined the occurrence of infection in the respiratory tract during the 4 preceding weeks. All the smokers with OPD-CB fulfilled the Global initiative for chronic Obstructive Lung Disease (GOLD) criteria for chronic obstructive pulmonary disease, with the exception that ventilatory lung capacity was assessed without prior bronchodilation, and were classified accordingly (stage I-IV). In accordance with previous praxis, ${ }^{1}$ the diagnosis of chronic bronchitis was based upon a history of phlegm at least 3 months in a row during 2 consecutive years. The smokers with OPD-CB were all current smokers (positive urine cotinine test [see Cotinine test section]), each

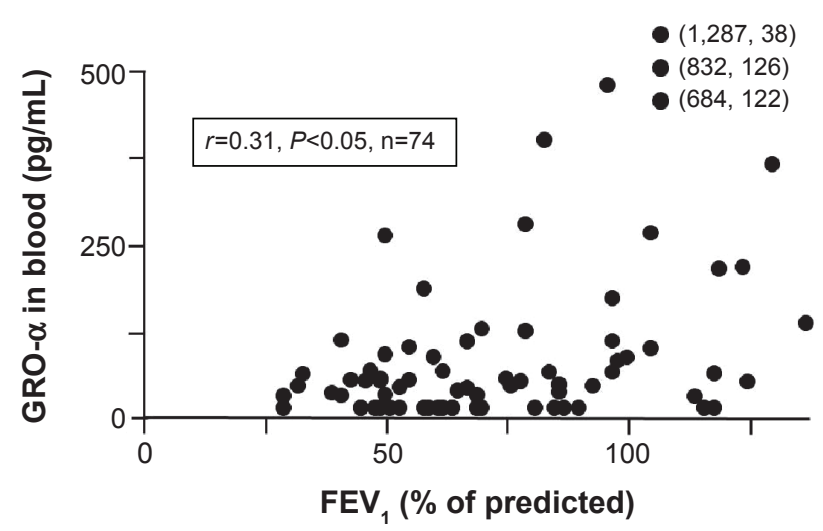

Figure SI Concentrations of growth-related oncogene (GRO)- $\alpha$ protein in blood (see "Materials and methods") versus ventilatory lung function (forced expiratory volume in I second $\left[\mathrm{FEV}_{1}\right]$ ) in the entire study population (ie, the pooled group of never-smokers, asymptomatic smokers, and smokers with obstructive pulmonary disease including chronic bronchitis) during stable clinical conditions at the time of inclusion.

Notes: Data are presented as individual values (circles), and the numbers in parentheses indicate observations "out of scale". The statistical analysis of correlation (in the box) was conducted using Spearman's rank correlation. one having a smoking history (tobacco load) of at least 10 pack-years.

We excluded patients with a history of asthma, atopy, or lung diseases other than obstructive pulmonary disease and chronic bronchitis, as well as patients with regular use of oral glucocorticoids. We also excluded patients with $\alpha 1$-antitrypsin deficiency, cancer, clinically significant heart failure, documented immunodeficiency, drug abuse, or known mental disorder.

During the course of our study, a total of four smokers with OPD-CB failed to complete participation according to the study protocol. Of these smokers, one died from an overdose of antidepressant drugs and another two were excluded owing to compliance problems and use of oral glucocorticoids. The fourth smoker stopped participation in the study prematurely, after visit 4 as specified below. At the time, this smoker had been diagnosed with a serious neurological disease. Data from the excluded smokers or other excluded subjects are not included in the study results we present in this manuscript.

As control subjects, we included ten asymptomatic current smokers with a tobacco load of at least 10 pack-years and ten healthy never-smokers; all these subjects were recruited via advertisement. These control subjects all had a normal lung function (see below for specific methods). They only attended one inclusion visit during stable clinical conditions, for sampling that was identical to that of the smokers with OPD-CB, with the exception of no sputum samples for bacterial culture being harvested. The clinical characteristics of the study subjects at the time of inclusion are presented in Table 1.

\section{Study design}

This study was prospective and all smokers and subjects were fully examined during stable clinical conditions at an inclusion visit. They also underwent lung function tests (see below), pulmonary X-ray, physical examination, blood tests, and a urine cotinine test to check for ongoing use of tobacco. The patients and subjects were also asked to fill in the European Community Respiratory Health Survey questionnaire to secure a correct diagnosis of chronic bronchitis. ${ }^{1}$

The included smokers with OPD-CB also donated spontaneous sputum samples for the culture of bacteria. During the subsequent 15 months, these smokers donated blood tests every 15 th week (during visit $2-5$ ). If the patient developed an exacerbation, an extra study visit was arranged for physical and radiological evaluation. At this occasion, the smoker with OPD-CB received all the regular treatment assessed 
Table SI C-reactive protein and inflammatory cells in blood at the time of inclusion and during exacerbations for smokers with OPD-CB

\begin{tabular}{lll}
\hline $\begin{array}{l}\text { Blood } \\
\text { concentrations }\end{array}$ & Inclusion & Exacerbation \\
\hline CRP $(\mathrm{mg} / \mathrm{L})$ & $2.0(0.3-19)$ & $6.5(0.3-300)^{*}$ \\
Leuko $\left(\times 10^{9} / \mathrm{L}\right)$ & $7.4(3.9-14.6)$ & $8.4(5.4-16)^{*}$ \\
Neu $\left(\times 10^{9} / \mathrm{L}\right)$ & $4.3(2-9.6)$ & $5.7(3.1-13)^{*}$ \\
Lym $\left(\times 10^{9} / \mathrm{L}\right)$ & $2.0(0.9-4.5)$ & $2.0(0.7-4.6)$ \\
Mono $\left(\times 10^{9} / \mathrm{L}\right)$ & $0.6(0.3-3.3)$ & $0.7(0.0-1.4)$ \\
Eos $\left(\times 10^{9} / \mathrm{L}\right)$ & $0.2(0.0-0.7)$ & $0.1(0.0-0.6)$ \\
\hline
\end{tabular}

Notes: Data for basophils are not shown since these cells were not present (see "Results"). Data are presented as median (range). Statistical comparison using Kruskal-Wallis test followed by Mann-Whitney U-test: $* P<0.05$ for concentration at exacerbation versus stable clinical conditions at the time of inclusion.

Abbreviations: CRP, C-reactive protein; Leuko, leukocytes; Neu, neutrophils; Lym, lymphocytes; Mono, monocytes; Eos, eosinophils.

to be adequate depending on his/her condition according to clinical routine, after a blood sample had rapidly been harvested. We consistently used the definition of chronic obstructive pulmonary disease exacerbations based on criteria described by Wedzicha and Donaldson ${ }^{2}$ and modified from Anthonisen et al. ${ }^{3}$

\section{Lung function tests}

All participating smokers and subjects underwent a careful assessment of ventilatory lung (dynamic spirometry) and gas diffusion capacity for carbon monoxide as described below. The determination of forced expiratory volume in 1 second and forced vital capacity was conducted utilizing a calibrated spirometer (Jaeger Masterscope ${ }^{\circledR}$; VIASYS Healthcare GmbH, Hoechberg, Germany and Sensormedics Vmax $22^{\circledR}$; VIASYS Healthcare, Yorba Linda, CA, USA). The gas diffusion capacity for carbon monoxide was assessed by the single-breath method with the standard equipment (SensorMedics $^{\circledR}$ 2200; SensorMedics ${ }^{\circledR}$ Co, Bilthoven, the Netherlands). We applied the reference values for spirometry

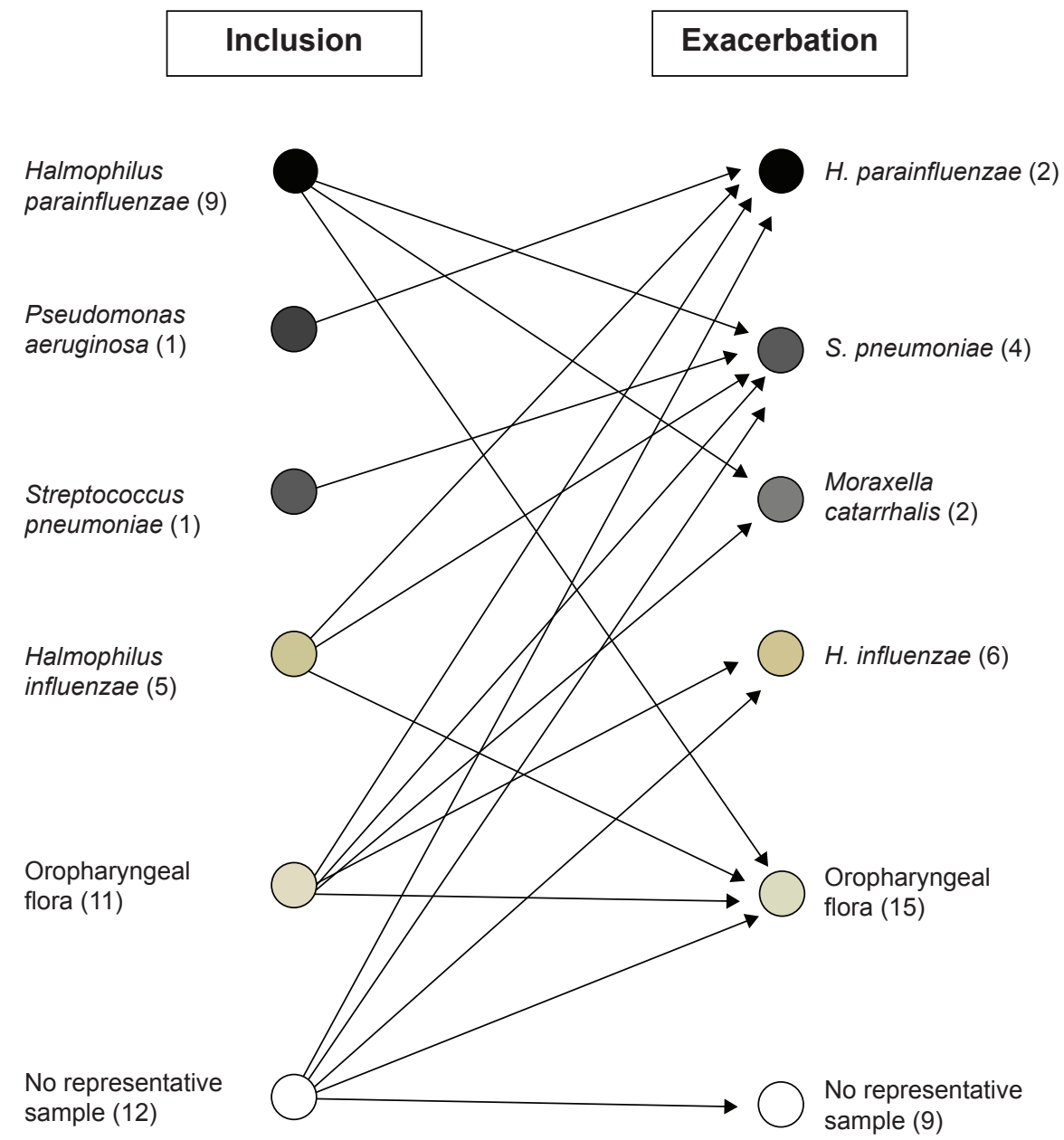

Figure S2 Overview of the growth of bacteria in sputum samples from smokers with obstructive pulmonary disease including chronic bronchitis during stable clinical conditions at the time of inclusion and during exacerbations.

Note: Data shown include the number of subjects $(n)$ with growth of each particular bacterial finding in sputum samples representative of the peripheral airways (see "Materials and methods"). 
from the European Respiratory Society ${ }^{4}$ and the reference values for gas diffusion capacity according to Salorinne. ${ }^{5}$

\section{Blood samples}

Samples of venous blood were collected from all subjects as described above. Blood cell differential counts were conducted and plasma as well as serum samples were prepared for analysis of inflammatory proteins. The concentrations of leukocytes (automated blood differential count analysis) (ADVIA 2120i Hematology system ${ }^{\circledR}$; Siemens, Duisburg, Germany) were determined at the accredited Department of Clinical Chemistry, Sahlgrenska University Hospital.

\section{C-reactive protein}

The measurement of C-reactive protein (CRP) (Tina-quant C-reactive protein high sensitive assay ${ }^{\circledR}$, HS No 1972944001 ; Hoffmann-La Roche Ltd, Basel, Switzerland) was conducted at the Department of Clinical Chemistry, Sahlgrenska University Hospital.

\section{IL-I 7 and GRO- $\alpha$ protein}

The concentrations of IL-17 (also known as IL-17A) protein in plasma and of GRO- $\alpha$ protein in serum were determined by using commercial and highly specific enzyme-linked immunosorbent assay kits (3520-1H-20; MabTech $^{\circledR}$, Nacka, Sweden and DY275; R\&D Systems, Inc, Minneapolis, MN, USA, respectively).

For IL-17, the concentration values that were below the lowest concentration of the standard curve $(1.56 \mathrm{pg} / \mathrm{mL})$ were assigned the arbitrary value of $0.8 \mathrm{pg} / \mathrm{mL}$ (the mean value of 0 and $1.56 \mathrm{pg} / \mathrm{mL}$ ). This was the case in 12 out of 69 samples at the time of inclusion. At this time point, one value exceeded the highest concentration of the standard curve $(400 \mathrm{pg} / \mathrm{mL})$ and was then assigned this particular value. Due to human error, samples from one asymptomatic smoker and one never-smoker control subject were lost and not included in this analysis for IL-17 protein.

For GRO- $\alpha$, the concentration values below the lowest concentration of the standard curve $(31 \mathrm{pg} / \mathrm{mL})$ were assigned the arbitrary value of $15.5 \mathrm{pg} / \mathrm{mL}$ (mean value of 0 and $31 \mathrm{pg} / \mathrm{mL}$ ). This was the case in 22 out of 73 samples at the time of inclusion and in five out of 32 samples during exacerbation. No GRO- $\alpha$ value exceeded the highest concentration of the standard curve $(2,000 \mathrm{pg} / \mathrm{mL})$ at any time point.

\section{IL-I 7 mRNA}

Blood samples were collected in PAXgene Blood RNA Tubes (Qiagen NV, Venlo, the Netherlands). Total RNA was isolated using the PAXgene Blood RNA Kit (Qiagen NV) according to the protocol. The cDNA was synthesized with the High Capacity cDNA Reverse Transcription Kit and random hexamer primers (Thermo Fisher Scientific, Waltham, MA, USA) with RNase inhibitor (Qiagen NV). Quantitative polymerase chain reaction (PCR) for IL-17A mRNA was performed using a TaqMan Universal PCR Master Mix kit and gene expression assay (Hs00174383_m1; Thermo Fisher Scientific) and human $\beta$-actin as the reference gene (assay Hs99999903_m1; Thermo Fisher Scientific). All reactions were run in duplicate with $10 \mathrm{ng}$ cDNA per reaction. The reactions were analyzed on a real-time PCR system (Viia7 Real-Time PCR system ${ }^{\circledR}$; Thermo Fisher Scientific).

\section{Sputum samples}

Immediately after harvest, the samples of spontaneous sputum were sent to the accredited laboratory of Bacteriology at Sahlgrenska University Hospital for a semiquantitative analysis of the growth of aerobic bacteria. These samples were also evaluated morphologically to ascertain that they were representative for the lower airways using light microscopy. Thus, samples in which squamous epithelial cells dominated were judged as not representative and were excluded. All samples were cultured under aerobic conditions and isolates $\left(10^{5} \mathrm{cfu} / \mathrm{mL}\right)$ were further analyzed according to standard bacteriological methods. A threshold concentration $\left(10^{6} \mathrm{cfu} / \mathrm{mL}\right)$ was used to define significant growth of bacteria in samples deemed representative of the peripheral airways.

\section{Cotinine test}

For qualitative detection of cotinine in urine, the major metabolite of nicotine in human urine, we used the One-Step Cotinine Test ${ }^{\circledR}$ (008A086; Ulti Med Products, Ahrensburg, Germany) and a cut-off concentration of $200 \mathrm{ng} / \mathrm{mL}$, all in accordance with the manufacturer's instructions.

\section{Statistical methods}

The descriptive and analytical statistical evaluation was conducted using standard computer software (SPSS ${ }^{\circledR} 16.0$ ). Nonparametric statistical methods were applied consistently. Comparisons of multiple groups were conducted utilizing Kruskal-Wallis followed by Mann-Whitney $U$-test, of two groups utilizing Kruskal-Wallis test, and correlation analyses were performed using Spearman's rank correlation test. A $P$-value $<0.05$ was deemed statistically significant. 


\section{References}

1. Burney PG, Luczynska C, Chinn S, Jarvis D. The European Community Respiratory Health Survey. Eur Respir J. 1994;7(5):954-960.

2. Wedzicha JA, Donaldson GC. Exacerbations of chronic obstructive pulmonary disease. Respir Care. 2003;48(12):1204-1213; discussion 1213-1215.

3. Anthonisen NR, Manfreda J, Warren CP, Hershfield ES, Harding GK, Nelson NA. Antibiotic therapy in exacerbations of chronic obstructive pulmonary disease. Ann Intern Med. 1987;106(2):196-204.
4. Quanjer PH, Tammeling GJ, Cotes JE, Pedersen OF, Peslin R, Yernault JC. Lung volumes and forced ventilatory flows. Report Working Party Standardization of Lung Function Tests, European Community for Steel and Coal. Official Statement of the European Respiratory Society. Eur Respir J Suppl. 1993;16:5-40.

5. Salorinne Y. Single-breath pulmonary diffusing capacity. Reference values and application in connective tissue diseases and in various lung diseases. Scand J Respir Dis Suppl. 1976;96:1-84.

\section{Publish your work in this journal}

The International Journal of COPD is an international, peer-reviewed journal of therapeutics and pharmacology focusing on concise rapid reporting of clinical studies and reviews in COPD. Special focus is given to the pathophysiological processes underlying the disease, intervention programs, patient focused education, and self management protocols.

\section{Dovepress}

This journal is indexed on PubMed Central, MedLine and CAS. The manuscript management system is completely online and includes a very quick and fair peer-review system, which is all easy to use. Visit $\mathrm{http} / / / \mathrm{www}$.dovepress.com/testimonials.php to read real quotes from published authors.

Submit your manuscript here: http://www.dovepress.com/international-journal-of-chronic-obstructive-pulmonary-disease-journal 